\title{
Assessment of genome integrity with array CGH in cattle transgenic cell lines produced by homologous recombination and somatic cell cloning
}

\author{
George E Liu', Yali Hou ${ }^{1,2}$, James M Robl ${ }^{3,4}$, Yoshimi Kuroiwa ${ }^{3^{*}}$ and Zhongde Wang ${ }^{3^{*}}$
}

\begin{abstract}
Background: Transgenic cattle carrying multiple genomic modifications have been produced by serial rounds of somatic cell chromatin transfer (cloning) of sequentially genetically targeted somatic cells. However, cloning efficiency tends to decline with the increase of rounds of cloning. It is possible that multiple rounds of cloning compromise the genome integrity or/and introduce epigenetic errors in the resulting cell lines, rendering a decline in cloning. To test these possibilities, we performed 9 high density array Comparative Genomic Hybridization (CGH) experiments to test the genome integrity in 3 independent bovine transgenic cell lineages generated from genetic modification and cloning. Our plan included the control hybridizations (self to self) of the 3 founder cell lines and 6 comparative hybridizations between these founders and their derived cell lines with either high or low cloning efficiencies.

Results: We detected similar amounts of differences between the control hybridizations (8, 13 and 39 differences) and the comparative analyses of both "high" and "low" cell lines (ranging from 7 to 57 with a mean of 20 ). Almost $75 \%$ of the large differences (>10 kb) and about $45 \%$ of all differences shared the same type (loss or gain) and were located in nearby genomic regions across hybridizations. Therefore, it is likely that they were not true differences but caused by systematic factors associated with local genomic features (e.g. GC contents).

Conclusions: Our findings reveal that large copy number variations are less likely to arise during genetic targeting and serial rounds of cloning, fortifying the notion that epigenetic errors introduced from serial cloning may be responsible for the cloning efficiency decline.
\end{abstract}

Keywords: genome integrity, cattle transgenic cell line, somatic cell cloning, array CGH

\section{Findings}

As embryonic stem cells are not available in the bovine species, somatic cells have been used for genetic modifications, and transgenic cattle have been produced from such genetically modified somatic cells by animal cloning. However, because primary somatic cells have limited life span and inevitably become senescent following DNA transfection and selection in cell culture, it is impossible to perform any further genetic modifications in these cells. Because of such, transgenic cattle with a

\footnotetext{
* Correspondence: yoshi@hematech.com; zwang@hematech.com ${ }^{3}$ Hematech Inc, Sioux Falls, SD, 57106, USA

Full list of author information is available at the end of the article
}

desired genotype that requires more than one genetic targeting event, such as homozygous deletion of the two alleles of a gene, cannot be produced. To overcome such limitations, a novel sequential genetic modification strategy in bovine somatic cells, for producing extensively genetically modified cattle, has been developed [1]. This process involves a serial round of genetic targeting events, each followed by cloning to rejuvenate the genetically modified somatic cells (to rescue them from senescence) for the next round of genetic targeting. Such genetically modified somatic cells are then subjected to a final round of cloning for producing transgenic animals with the desired genotypes. While 
multiple genomic loci have been modified by this strategy, cloning efficiency tends to decline with the increased rounds of cloning, and in some severe cases, such manipulated cells can become unclonable (no live calf can be cloned from them) [2]. It is yet unknown whether the cloning efficiency declines in such derived cells are due to genetic abnormalities caused by the multiple genetic targeting or/and serial cloning process or due to the accumulation of epigenetic errors introduced during these processes. Such questions are fundamental in farm animal transgenesis, as somatic cells and cloning are currently the only choices for genetic modifications and for transgenic animal production in the domestic animal species.

To investigate whether the declines of cloning efficiency in the cloned bovine transgenic cell lines are due to large genomic deletions or insertions, 9 high density array Comparative Genomic Hybridization (CGH) experiments were performed to test the genome integrity in 3 independent bovine transgenic cell lineages. Array CGH allows the entire genome to be assayed for the gain or loss of material in a single experiment by measuring the relative hybridization intensity between fluorescently labeled test and reference DNA samples. It has been widely used in the detection of copy number variations (CNVs). One objective of this study is to develop array CGH into a systematic test for the genomic integrity of donor cells after each round of genetic modification before they are used as donors for producing transgenic animals.

We selected 3 independent cell lineages from our transgenic bovine cell line collection. Each lineage includes the founder and two derived cell lines, which demonstrated dramatic differences in cloning efficiency (Figure 1). The cloning efficiencies are represented by the live calf counts at birth divided by recipient numbers used for embryo transfer as shown in parentheses. Test lines were classified into "high $(\mathrm{H})$ " and "low (L)" based on their cloning efficiencies, with 7\%-42\% live calving rates designated as high and $0 \%$ as low. The procedures for genetic modifications, animal cloning and transgenic cell line establishment were described previously [1]. Genomic DNA samples were purified from the cell lines using Qiagen Miniprep Kit as recommended by the manufacturer. All DNA samples were analyzed by Nanodrop spectrophotometer and agarose gel electrophoresis. Nine array CGH experiments were carried out using each cell line as the test sample and the corresponding founder line as the reference sample (Table 1). Therefore, our plan included the control hybridizations of the 3 founder cell lines (self to self) and 6 comparative hybridizations between these founders and their

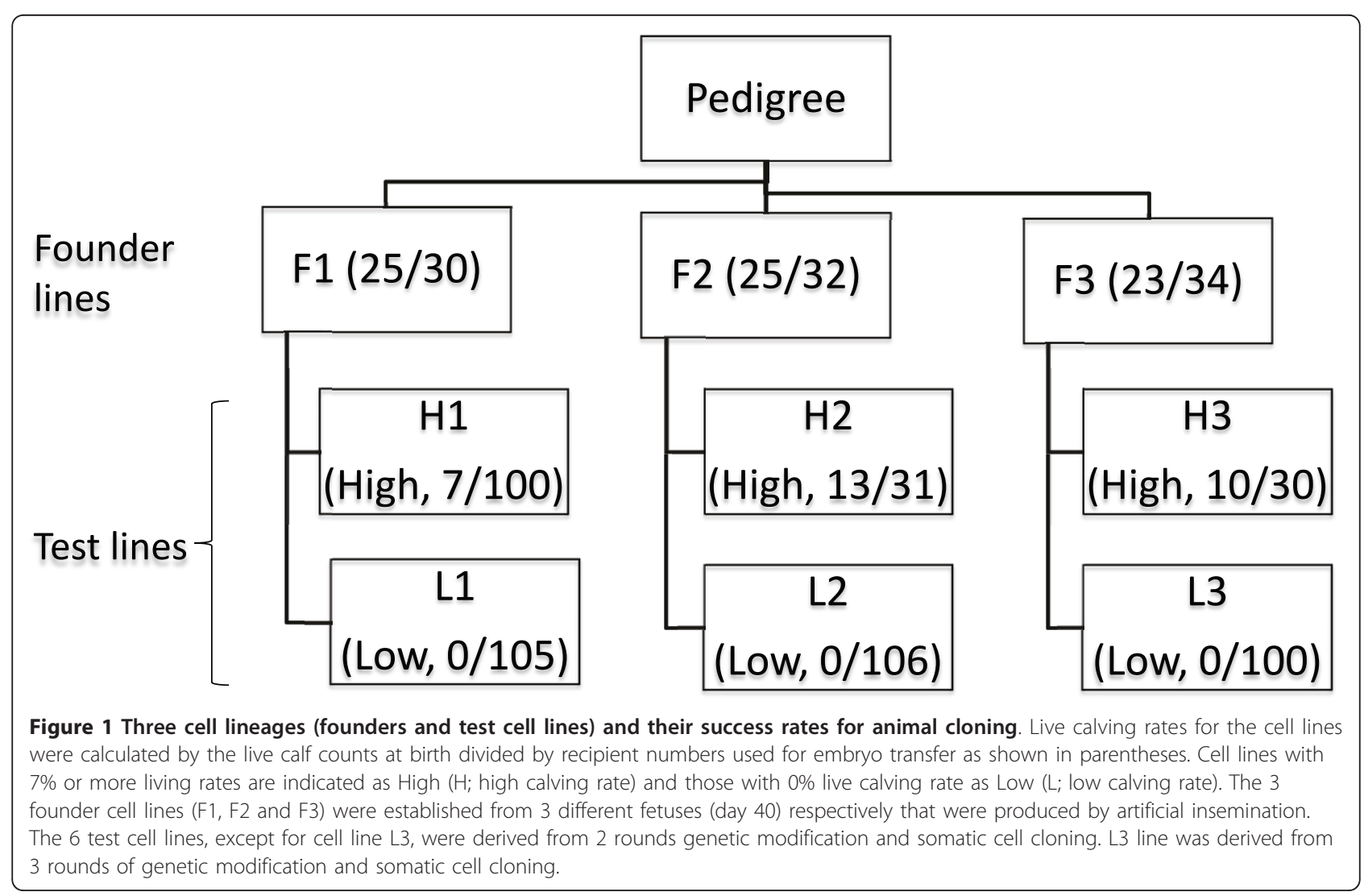


Table 1 Hybridization plan and event counts

\begin{tabular}{lllll}
\hline No & Test & Ref & Type & Events \\
\hline 1 & F1 & F1 & Self1 & 13 \\
2 & H1 & F1 & High1 & 13 \\
3 & L1 & F1 & Low1 & 7 \\
4 & F2 & F2 & Self2 & 8 \\
5 & H2 & F2 & High2 & 7 \\
6 & L2 & F2 & Low2 & 57 \\
7 & F3 & F3 & Self3 & 39 \\
8 & H3 & F3 & High3 & 17 \\
9 & L3 & F3 & Low3 & 22 \\
10 & Dt & Dt & Self4 & 3 \\
\hline
\end{tabular}

derived cell lines of extreme phenotypes ("high" versus "low" cloning efficiencies). Another self to self control hybridization was performed using the sequenced Hereford cow L1 Dominette 01449 (Dt, American Hereford Association registration number 42190680). Each CGH array contains $\sim 2.1$ million oligonucleotide probes that provide a genome-wide coverage with an average interval of $\sim 1.2 \mathrm{~kb}$ (kilo basepairs) on the UMD3 genome assemblies [3]. DNA labeling, hybridizations, array scanning, data normalization, and segmentation were performed as described before $[4,5]$. The genomic variations were represented by gains and losses of normalized fluorescence intensities relative to the reference. The calls are filtered according to the similar criteria as described previously [6]. Briefly, we tested a series of $\log 2$ ratio shift and affected neighboring probe counts and their impact on the false discovery rate in the selfself control hybridizations. We then selected a calling criterion, requiring that alternations of $0.5 \log 2$ ratios over 5 neighboring probes, under which minimal false positives were found for self-self control hybridizations. Thus, the arrays have a resolution of approximately 4.8 $\mathrm{kb}$. Nine array CGH data have been submitted to the gene expression omnibus (http://www.ncbi.nlm.nih.gov/ geo/) under the accession number GSE26132.

We detected 8, 13 and 39 differences in 3 control hybridizations. Similar amounts of differences (ranging from 7 to 57 with a mean of $\sim 20$ ) were detected in comparative analyses of both "high" and "low" derived cell lines (Table 1 and Table 2). We also made event calls on Btau_4.0 and obtained a comparable number of events (data not shown). Almost $75 \%$ of the large differences (>10 kb, 42/58 events in Table 2) and about $45 \%$ of all differences (82/186 events) shared the same type (loss or gain) and were located in nearby genomic regions across hybridizations. Therefore, it is likely that they were not true differences but instead caused by systematic factors like dye bias (Cy3 versus $\mathrm{Cy} 5)$ or genomic waves associated with local genomic features, such as GC contents [7]. For example, a variable region of
Table 2 Copy number variation events larger than 10 kb

\begin{tabular}{|c|c|c|c|c|c|c|c|}
\hline No & Type & Chr & Start & End & Length & $\log R$ & Shared \\
\hline \multirow[t]{3}{*}{1} & Self1 & chr13 & $48,998,999$ & $49,016,999$ & 18,000 & 0.5168 & Yes \\
\hline & & chr3 & $1,020,294$ & $1,039,699$ & 19,405 & 0.6721 & Yes \\
\hline & & chr4 & $41,465,452$ & $41,496,569$ & 31,117 & 0.6946 & Yes \\
\hline \multirow[t]{4}{*}{2} & High1 & chr13 & $48,992,999$ & $49,010,999$ & 18,000 & 0.6269 & Yes \\
\hline & & chr3 & $1,020,294$ & $1,039,699$ & 19,405 & 0.6410 & Yes \\
\hline & & chr4 & $33,570,495$ & $33,584,300$ & 13,805 & 0.5216 & Yes \\
\hline & & chr4 & $41,465,452$ & $41,496,569$ & 31,117 & 0.5674 & Yes \\
\hline \multirow[t]{4}{*}{3} & Low1 & chr13 & $48,991,360$ & $49,017,997$ & 26,637 & 0.6818 & Yes \\
\hline & & chr29 & $19,400,430$ & $19,449,274$ & 48,844 & 0.5343 & Yes \\
\hline & & chr3 & $1,020,294$ & $1,042,839$ & 22,545 & 0.7566 & Yes \\
\hline & & chr4 & $41,465,452$ & $41,496,569$ & 31,117 & 0.8130 & Yes \\
\hline \multirow[t]{3}{*}{4} & Self2 & chr13 & $48,991,360$ & $49,017,997$ & 26,637 & 0.5172 & Yes \\
\hline & & chr3 & $1,020,294$ & $1,042,839$ & 22,545 & 0.6039 & Yes \\
\hline & & chr4 & $41,465,452$ & $41,496,569$ & 31,117 & 0.5761 & Yes \\
\hline 5 & High2 & chr25 & $32,373,045$ & $32,464,814$ & 91,769 & 0.6769 & Yes \\
\hline \multirow[t]{5}{*}{6} & Low2 & chr11 & $87,532,580$ & $87,543,090$ & 10,510 & -0.5617 & No \\
\hline & & chr2 & $16,958,057$ & $16,968,620$ & 10,563 & -0.5814 & No \\
\hline & & chr25 & $32,374,157$ & $32,471,634$ & 97,477 & -0.8136 & Yes \\
\hline & & chr29 & $43,204,051$ & $43,223,301$ & 19,250 & -0.5334 & No \\
\hline & & $\operatorname{chrX}$ & $10,447,331$ & $10,457,486$ & 10,155 & -0.9137 & No \\
\hline \multirow[t]{18}{*}{7} & Self3 & chr1 & $5,249,999$ & $5,285,999$ & 36,000 & 0.5481 & Yes \\
\hline & & chr10 & $59,478,526$ & $59,531,204$ & 52,678 & 0.5501 & No \\
\hline & & chr13 & $48,991,360$ & $49,017,997$ & 26,637 & 0.6809 & Yes \\
\hline & & chr15 & $26,576,999$ & $26,602,199$ & 25,200 & 0.6474 & Yes \\
\hline & & chr2 & & & & & No \\
\hline & & chr25 & $32,374,157$ & $32,471,634$ & 97,477 & -0.6113 & Yes \\
\hline & & chr29 & $19,399,250$ & $19,449,274$ & 50,024 & 0.6094 & Yes \\
\hline & & chr3 & $1,020,294$ & $1,039,699$ & 19,405 & 0.8678 & Yes \\
\hline & & chr4 & $27,707,990$ & $27,750,008$ & 42,018 & 0.5614 & No \\
\hline & & chr4 & $41,465,452$ & $41,496,569$ & 31,117 & 0.8426 & Yes \\
\hline & & chr6 & $45,738,703$ & $45,776,348$ & 37,645 & 0.5049 & Yes \\
\hline & & chr6 & $89,209,799$ & $89,220,599$ & 10,800 & 0.6477 & Yes \\
\hline & & chr8 & $36,073,799$ & $36,145,799$ & 72,000 & 0.5122 & Yes \\
\hline & & chrX & $37,290,568$ & $37,303,155$ & 12,587 & 0.8150 & No \\
\hline & & chrX & $37,564,199$ & $37,614,599$ & 50,400 & 0.5427 & No \\
\hline & & $\operatorname{chrX}$ & $56,120,456$ & $56,149,298$ & 28,842 & 0.6124 & No \\
\hline & & $\operatorname{chr} x$ & $84,230,177$ & $84,255,543$ & 25,366 & 0.5679 & No \\
\hline & & chrX & $138,374,999$ & $138,386,999$ & 12,000 & 0.5528 & No \\
\hline \multirow[t]{6}{*}{8} & High3 & chr13 & $48,993,325$ & $49,013,328$ & 20,003 & 0.5149 & Yes \\
\hline & & chr15 & $26,576,999$ & $26,602,199$ & 25,200 & 0.6022 & Yes \\
\hline & & chr25 & $32,374,157$ & $32,403,637$ & 29,480 & -0.8278 & Yes \\
\hline & & chr4 & $33,564,599$ & $33,578,999$ & 14,400 & 0.5363 & Yes \\
\hline & & chr4 & $41,466,599$ & $41,495,399$ & 28,800 & 0.5097 & Yes \\
\hline & & chr6 & $45,744,065$ & $45,772,999$ & 28,934 & 0.5284 & Yes \\
\hline \multirow[t]{7}{*}{9} & Low3 & chr1 & $5,249,999$ & $5,285,999$ & 36,000 & 0.5559 & Yes \\
\hline & & chr1 & $144,107,850$ & $144,130,905$ & 23,055 & 0.5949 & No \\
\hline & & chr13 & $48,991,360$ & $49,017,997$ & 26,637 & 0.6031 & Yes \\
\hline & & chr17 & $73,139,605$ & $73,159,081$ & 19,476 & -2.0603 & No \\
\hline & & chr18 & $6,080,815$ & $6,121,152$ & 40,337 & -0.5749 & No \\
\hline & & chr25 & $32,362,844$ & $32,470,747$ & 107,903 & 0.6669 & Yes \\
\hline & & chr29 & $19,412,812$ & $19,444,215$ & 31,403 & 0.6690 & Yes \\
\hline
\end{tabular}


Table 2 Copy number variation events larger than 10 kb (Continued)

\begin{tabular}{rcccccc}
\hline chr3 & $1,020,599$ & $1,038,599$ & 18,000 & 0.6787 & Yes \\
chr4 & $33,564,599$ & $33,578,999$ & 14,400 & 0.6100 & Yes \\
chr4 & $41,465,452$ & $41,487,890$ & 22,438 & 0.6229 & Yes \\
chr6 & $89,208,198$ & $89,218,288$ & 10,090 & 0.6937 & Yes \\
& chr8 & $36,077,399$ & $36,152,999$ & 75,600 & 0.5089 & Yes \\
& chrU & $12,620,478$ & $12,665,758$ & 45,280 & 0.7441 & No \\
$10 \quad$ Self4 & chr13 & $48,992,999$ & $49,010,999$ & 18,000 & 0.5729 & Yes \\
\hline
\end{tabular}

Chr: chromosome, Log R: log2Ratio, Shared: Yes/No - events shared among samples (i.e. hybridizations) or not.

chr25:27220643-27226199 from UMD3 (5.5 kb) was found in hybridizations of High1, Self3 and High3. Using liftOver, we migrated this region to its corresponding region at chr25:28829889-28835660 on Btau_4.0. The GC\% track and array CGH probe track are shown in the UCSC genome browser snapshot (Figure 2). Although each probe has a GC\% range from $42-48 \%$, the average GC\% of this region (53.5\%) is significantly higher than the cattle genome average of $41.7 \%$ and multiple GC\% peaks exist in the close proximity of 3 out of the 6 probes. Out of 186 events, 129 events are unique after merging the overlapped events (data not shown). Out of these 129 unique events, 71 events can be successfully migrated from UMD3 to Btau_4.0 and all of them showed various degrees of higher GC contents as compared to the genome average.

In this project, we employed array CGH to study genomic integrity in cattle transgenic cell lines. This highresolution genome-wide survey fills the knowledge gaps left out in the existing literature. Our results generate a valuable tool for genomic integrity evaluation and largely exclude the occurrences of large genomic structural variations $(\geq 10 \mathrm{~kb})$ during animal cloning, supporting our recent findings that epigenetic errors introduced by multiple rounds of cloning and/or genetic targeting are the possible underlying causes for the cloning efficiency decline $[8,9]$. However, this initial genomic integrity survey reported here is probably not complete as the CGH arrays were designed by using only one reference genome. As a result, sequences absent in Dominette and present in other animals cannot be ascertained. Also, array $\mathrm{CGH}$ cannot detect small event $(<5 \mathrm{~kb})$ and balanced events like inversions and translocations. Therefore, we cannot totally exclude the possibility that both genetic and epigenetic influences may be at work and genetic differences may have played a role in the low efficiencies. With the costs of genome sequencing dropping dramatically by using next-generation sequencing, emerging high-quality cattle genomic sequence will soon facilitate the application of the direct sequence comparison strategy. Furthermore, additional studies like epigenomics are warranted and may unravel the epigenetic basis for the successful and efficient animal cloning.

\section{Acknowledgements and Funding}

We thank D. Hebert, A. Edwards and W. Gang for technical assistance.

\section{Author details}

'USDA-ARS, ANRI, Bovine Functional Genomics Laboratory, Beltsville, Maryland 20705, USA. ${ }^{2}$ Department of Animal and Avian Sciences, University of Maryland, College Park, Maryland 20742, USA. ${ }^{3}$ Hematech Inc, Sioux Falls, SD, 57106, USA. ${ }^{4} 48351,277$ th Street, Canton, SD, 57013, USA.

\section{Authors' contributions}

GEL and ZW conceived and designed the experiments. JMR provided reagents. GEL and YH performed in silico prediction and computational analyses. GEL, YK and ZW wrote the paper.

All authors have read and approved the final manuscript.

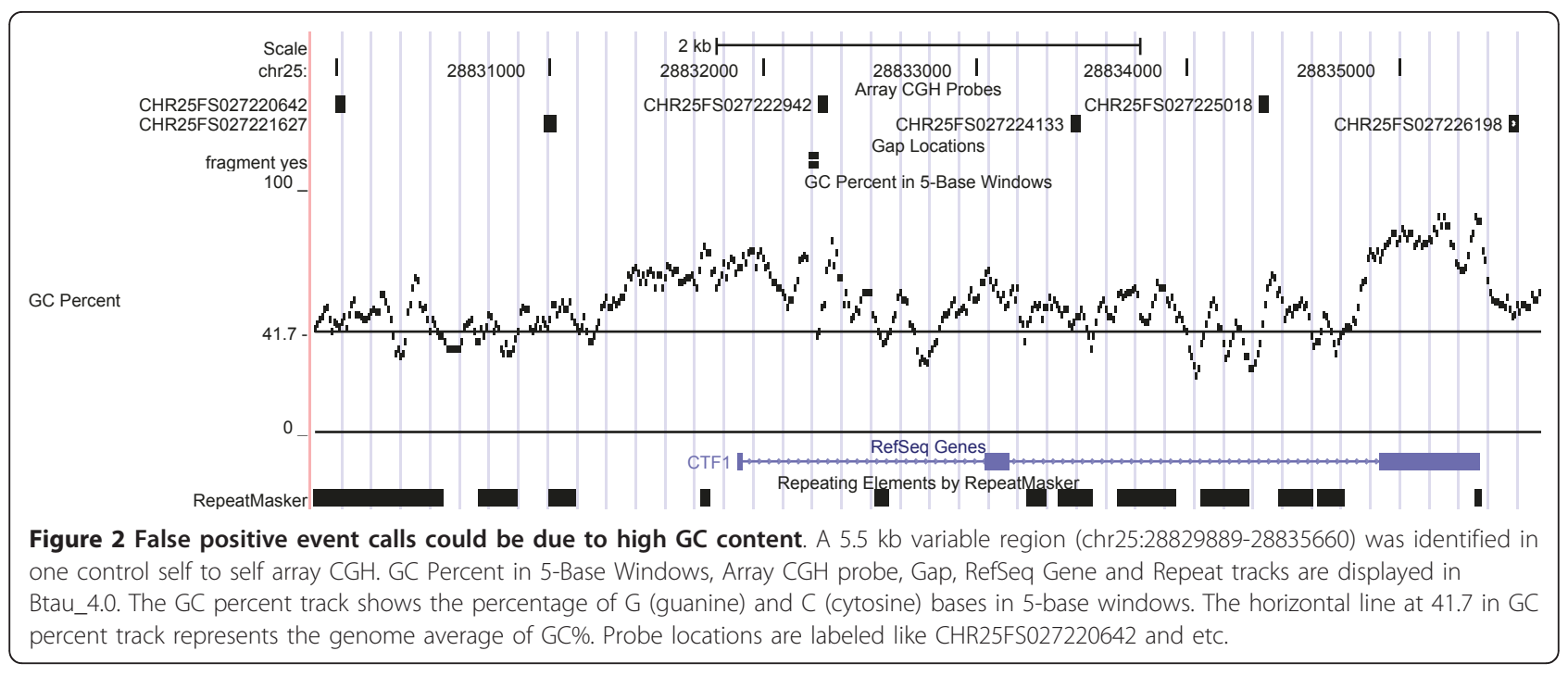




\section{Competing interests}

YK and ZW are employees of Hematech, Inc., a subsidiary of Kyowa Hakko Kirin Company, Ltd. The authors declare that they have no competing interests.

Received: 18 January 2011 Accepted: 23 May 2011

Published: 23 May 2011

\section{References}

1. Kuroiwa $Y$, Kasinathan $P$, Sathiyaseelan T, Jiao JA, Matsushita $H$, Sathiyaseelan J, Wu H, Mellquist J, Hammitt M, Koster J, Kamoda S, Tachibana K, Ishida I, Robl JM: Antigen-specific human polyclonal antibodies from hyperimmunized cattle. Nat Biotechnol 2009, 27:173-181.

2. Kuroiwa $Y$, Kasinathan P, Matsushita $H$, Sathiyaselan J, Sullivan EJ, Kakitani $M$, Tomizuka K, Ishida I, Robl JM: Sequential targeting of the genes encoding immunoglobulin-mu and prion protein in cattle. Nat Genet 2004, 36:775-780.

3. Zimin AV, Delcher AL, Florea L, Kelley DR, Schatz MC, Puiu D, Hanrahan F, Pertea G, Van Tassell CP, Sonstegard TS, Marcais G, Roberts M, Subramanian P, Yorke JA, Salzberg SL: A whole-genome assembly of the domestic cow, Bos taurus. Genome Biol 2009, 10:R42.

4. Olshen $A B$, Venkatraman ES, Lucito R, Wigler M: Circular binary segmentation for the analysis of array-based DNA copy number data. Biostatistics 2004, 5:557-572.

5. Selzer RR, Richmond TA, Pofahl NJ, Green RD, Eis PS, Nair P, Brothman AR, Stallings RL: Analysis of chromosome breakpoints in neuroblastoma at sub-kilobase resolution using fine-tiling oligonucleotide array CGH. Genes Chromosomes Cancer 2005, 44:305-319.

6. Liu GE, Hou Y, Zhu B, Cardone MF, Jiang L, Cellamare A, Mitra A, Alexander L, Coutinho LL, Dell'aquila ME, Gasbarre LC, Lacalandra G, Li RW, Matukumalli LK, Nonneman D, Regitano LC, Smith TP, Song J, Sonstegard TS, Van Tassell CP, Ventura M, Eichler EE, McDaneld TG, Keele JW: Analysis of copy number variations among diverse cattle breeds. Genome Res 2010, 20:693-703.

7. Marioni JC, Thorne NP, Valsesia A, Fitzgerald T, Redon R, Fiegler $\mathrm{H}_{\text {, }}$ Andrews TD, Stranger BE, Lynch AG, Dermitzakis ET, Carter NP, Tavare S, Hurles ME: Breaking the waves: improved detection of copy number variation from microarray-based comparative genomic hybridization. Genome Biol 2007, 8:R228.

8. Rodriguez-Osorio N, Wang Z, Kasinathan P, Page GP, Robl JM, Memili E: Transcriptional reprogramming of gene expression in bovine somatic cell chromatin transfer embryos. BMC Genomics 2009, 10:190.

9. McLean CA, Wang Z, Babu K, Edwards A, Kasinathan P, Robl J, Sheppard AM: Normal development following chromatin transfer correlates with donor cell initial epigenetic state. Anim Reprod Sci 2010, 118:388-393.

doi:10.1186/2041-9414-2-6

Cite this article as: Liu et al: Assessment of genome integrity with array CGH in cattle transgenic cell lines produced by homologous recombination and somatic cell cloning. Genome Integrity 2011 2:6,

\section{Submit your next manuscript to BioMed Central and take full advantage of:}

- Convenient online submission

- Thorough peer review

- No space constraints or color figure charges

- Immediate publication on acceptance

- Inclusion in PubMed, CAS, Scopus and Google Scholar

- Research which is freely available for redistribution

Submit your manuscript at www.biomedcentral.com/submit
Biomed Central 